\title{
High Temperature Properties Research of Reactive Powder Concrete
}

\author{
Shaowei $\mathrm{Yao}^{\mathrm{a}}$,Man Zhao \\ Hebei Provincial Key Laboratory of Inorganic Nonmetallic Materials; College of Materials Science \\ and Engineering, North China University of science and Technology; Tangshan 063009, China \\ ayaoshaowei389@163.com
}

Keywords: reactive powder concrete; compression strength; microstructure

Abstract: Reactive powder concrete is a kind of high performance concrete. In this paper, it is analyzed that two kinds of fibers RPC on appearance, mass loss, the compressive strength at the different high temperature and the microstructure after high temperatures.

\section{Introduction}

Compared with ordinary concrete, high performance concrete structure is compact, more brittle, low permeability, cause its fire resistance is poor, burst probability significantly greater than ordinary concrete under fire.[1] The microstructure of concrete after different high temperature change determines its macroscopic mechanical properties after high temperature change rule, through comparing with all kinds of fiber and without fiber concrete compressive strength and microstructure, to evaluate the damage degree of concrete structures after fire and the reinforcement measures is of great significance. ${ }^{[2]}$

\section{Experiment}

Material preparation: cement: the cement for test is P.O42.5 levels of ordinary Portland cement (Tangshan Jidong). Silica fume: the mass fraction of $94.5 \% \mathrm{SiO}_{2}$, specific surface area of 20780 $\mathrm{m}^{2} / \mathrm{kg}$; Slag powder: specific surface area is $4750 \mathrm{~cm}^{2} / \mathrm{g}$, S95 type; Silica sand: The mass fraction of $\mathrm{SiO}_{2}$ for more than $99.6 \%, 40 \sim 70$ mesh and 70 140 of silica sand. Polypropylene fiber: length of $18 \sim 20 \mathrm{~mm}$, the melting point is $165^{\circ} \mathrm{C}$; Copper coated steel fiber: $0.2213 \mathrm{~mm}$, diameter of $0.22 \mathrm{~mm}$; Additive: brown powder FDN concentrated high efficiency water reducing agent.

Experimental process: firstly you should put the quartz sand, cement, silica fume, slag, fiber and so on into the blender, dry mixing 3 minutes. Then you need add water and water reducing agent and wet mixing 6 minutes, the ratio of each made into eight groups. $70 \times 70 \times 70 \mathrm{~mm}$ specimen, and after $24 \mathrm{~h}$ open mold, the standard curing room curing $28 \mathrm{~d}$ out to dry, set aside. Ratio is shown in the Table1. Next the dried specimen will be weighing, respectively in $200{ }^{\circ} \mathrm{C}, 300{ }^{\circ} \mathrm{C}, 400{ }^{\circ} \mathrm{C}, 500{ }^{\circ} \mathrm{C}$, $600{ }^{\circ} \mathrm{C}, 700{ }^{\circ} \mathrm{C}, 800{ }^{\circ} \mathrm{C} 120$ minutes, cooling to room temperature and weighing, measuring the compression strength and microstructure.

Table1 RPC concrete mixture ratio $\left[\mathrm{kg} / \mathrm{m}^{3}\right]$

\begin{tabular}{ccccccccc}
\hline NO. & Cement & $\begin{array}{c}\text { Silica } \\
\text { fume }\end{array}$ & Slag & $\begin{array}{c}\text { Silica } \\
\text { Sand }\end{array}$ & Additive & Water & $\begin{array}{c}\text { Steel } \\
\text { fiber }\end{array}$ & PP fiber \\
\hline 1 & 816.87 & 245.06 & 122.53 & 980.25 & 47.28 & 236.89 & 0 & 0 \\
2 & 800.53 & 240.16 & 120.08 & 960.64 & 46.43 & 232.15 & 156 & 0 \\
3 & 815.24 & 244.57 & 122.29 & 978.28 & 47.28 & 236.42 & 0 & 1.82 \\
4 & 798.90 & 239.67 & 119.84 & 958.68 & 46.43 & 231.68 & 156 & 1.82 \\
\hline
\end{tabular}




\section{Results and discussion}

Results of specimen quality loss after high temperature are shown in Table 2.

Table 2 RPC quality loss after high temperature [\%]

\begin{tabular}{cccccccc}
\hline NO. & $200^{\circ} \mathrm{C}$ & $300^{\circ} \mathrm{C}$ & $400^{\circ} \mathrm{C}$ & $500^{\circ} \mathrm{C}$ & $600^{\circ} \mathrm{C}$ & $700^{\circ} \mathrm{C}$ & $800^{\circ} \mathrm{C}$ \\
\hline 1 & 1.58 & 2.79 & 4.32 & 4.38 & 4.69 & 5.03 & 7.63 \\
2 & 1.82 & 3.18 & 8.27 & 8.90 & 9.60 & 9.69 & 10.97 \\
3 & 2.83 & 4.21 & 8.50 & 10.14 & 10.19 & 10.27 & 10.42 \\
4 & 4.47 & 5.22 & 8.79 & 9.98 & 10.66 & 11.02 & 11.29 \\
\hline
\end{tabular}

As can be seen from Table 2, the mass loss is as basic: $4>3>2>1$ group. First, the mass loss is mainly the capillary water evaporation; Temperature, a small amount of fine crack formation, mass loss increase, mainly for the gel water evaporation; Temperature continue to rise, small cracks continue to increase, began to appear a small amount of crack width, the major loss of water of crystallization and $\mathrm{Ca}(\mathrm{OH})_{2}$ decomposition; while $600-800^{\circ} \mathrm{C}$, appear a large number of random crack width, crack and interpenetration, hydrated calcium silicate and $\mathrm{CaCO}_{3}$ decomposition, the largest mass loss.

Compressive strength of specimens after high temperature are shown in Table 3.

Table 3 the RPC compressive strength after high temperature [MPa]

\begin{tabular}{ccccccccc}
\hline NO. & $20^{\circ} \mathrm{C}$ & $200^{\circ} \mathrm{C}$ & $300^{\circ} \mathrm{C}$ & $400^{\circ} \mathrm{C}$ & $500^{\circ} \mathrm{C}$ & $600^{\circ} \mathrm{C}$ & $700^{\circ} \mathrm{C}$ & $800^{\circ} \mathrm{C}$ \\
\hline 1 & 70.09 & 69.08 & 72.08 & 71.02 & 66.62 & 62.62 & 51.42 & 34.61 \\
2 & 95.17 & 99.46 & 104.50 & 119.41 & 101.43 & 79.57 & 52.27 & 39.68 \\
3 & 45.45 & 60.84 & 63.83 & 57.99 & 53.48 & 47.28 & 42.46 & 32.87 \\
4 & 70.94 & 70.44 & 76.34 & 101.32 & 74.49 & 55.72 & 54.53 & 50.89 \\
\hline
\end{tabular}

Single steel fiber, polypropylene fiber or mixed with fiber and polypropylene fiber can effectively prevent the RPC burst; Compressive strength increases with temperature increases first and then. Incorporation of steel fiber can improve compressive strength of RPC, with the temperature increasing of experience, the failure characteristics with normal temperature similar to that of brittle failure. When the temperature is below $600^{\circ} \mathrm{C}$, the PP fiber have adverse effects on RPC compressive strength; When the temperature higher than $600{ }^{\circ} \mathrm{C}$, the mixed PP fiber can improve compressive strength of RPC.

Reason: reactive powder concrete containing silica fume, slag, such as active admixture, after less than $400{ }^{\circ} \mathrm{C}$ high temperature effect, is equivalent to experience the process of high temperature curing, make secondary hydration reaction more fully, strength than normal temperature also increase accordingly. Steel fiber mixed with inhibiting the volume change due to the rapid temperature change of concrete. In addition, the steel fiber has good heat transfer performance and can reduce the temperature stress with the concrete inside and outside temperature gradient. So adding steel fiber can effectively improve the RPC compressive strength after high temperature; 
Polypropylene fiber with low melting point, after melting interconnected holes for vapor overflow channel, can prevent the RPC burst at high temperature, but also increased the internal defects of $\mathrm{RPC}$, so the compressive strength decreases with the mixed PP fiber.

Microstructure are shown in Fig. 1, Fig. 2, Fig. 3 and Fig. 4.

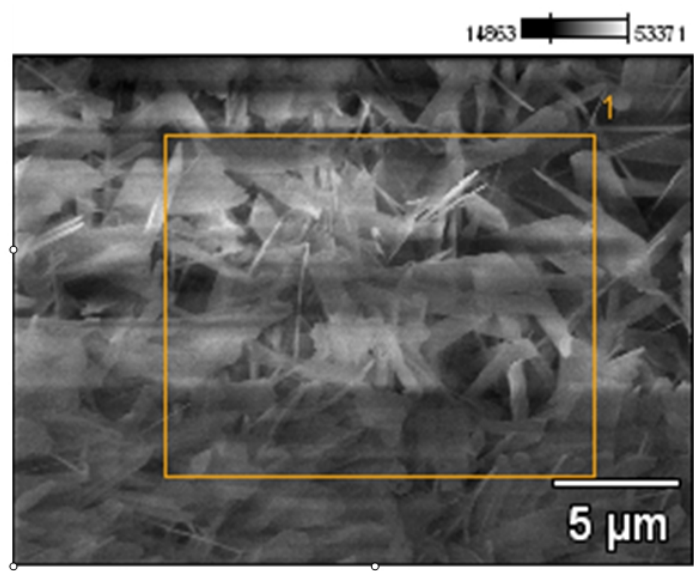

Fig. $1400^{\circ} \mathrm{C}$ RPC SEM

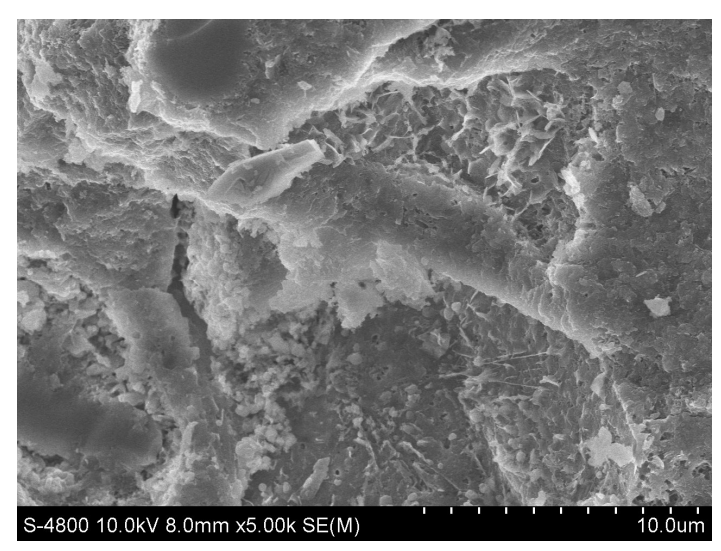

Fig. $3400^{\circ}$ Cmixing PP fiber RPC SEM

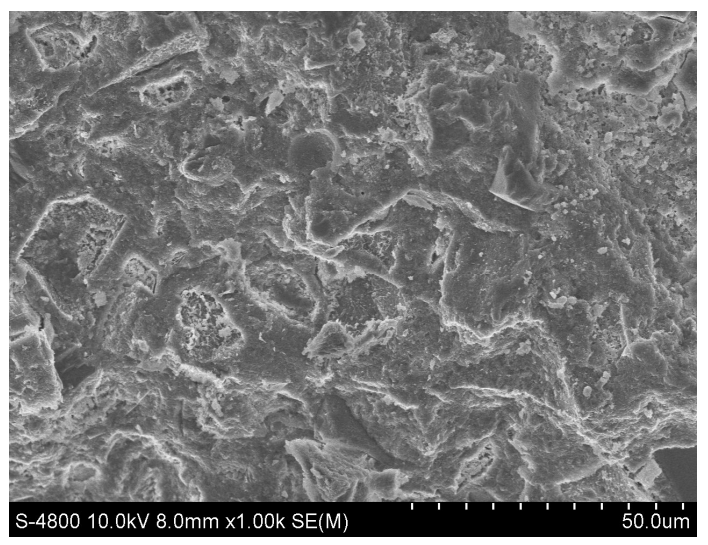

Fig. $2400^{\circ} \mathrm{C}$ steel fiber and the bonding interface of SEM

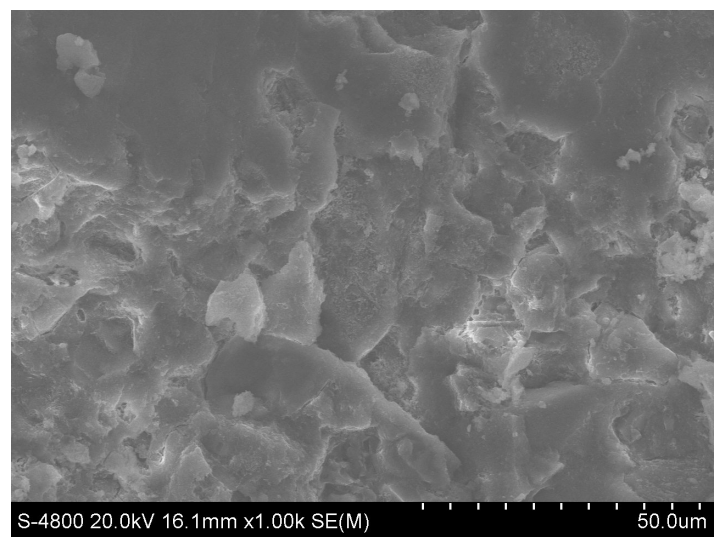

Fig. $4400^{\circ} \mathrm{C}$ mixed with fiber RPC SEM

It is shown that C-S-H gel consists of flat particle accumulation dense rock body into large pieces of dispersed phase, lamination and crack after high temperature. ${ }^{[3]}$ Between cement paste and silica sand aggregate interface transition zone with the increase of heating temperature cracks and has a tendency to further widening gradually, even aggregate appear damage phenomenon, serious influence the macroscopic mechanical properties of RPC. Adding polypropylene fiber RPC after high temperature, forming inside the holes is easy to produce stress concentration, the intensity is reduced.

\section{Conclusions}

(1) Mass loss increases with temperature rising gradually, tiny crack continues to increase, the crack width increase. With the same temperature, mass loss after adding fiber increased. 
(2) With the temperature rising of RPC, compressive strength is presented first increases and then rule: $300^{\circ} \mathrm{C} 400^{\circ} \mathrm{C}$ high strength and $600{ }^{\circ} \mathrm{C}$ decreased obviously. Steel fiber can effectively improve the RPC compressive strength after high temperature, high temperature PP fiber can prevent the RPC when blowout, but will reduce its compressive strength.

\section{Acknowledgements}

This work was financially supported by the Hebei Province Science and Technology Plan Project (16273706D).

\section{References}

[1] Gaifei Peng, Yannian Chen, Naiqian Feng. Performance attenuation characteristics of high strength concrete subjected to high temperature. Concrete [J], 1: 16-19, (1999)

[2] Hongbin Liu, Kangle Li, Yang Ju, Huijie Wang, Jinbo wang, Kaipei Tian, Song Wei. High temperature burst test of steel fiber reactive powder concrete research. Concrete [J], No. "- 8,( 2010)

[3] Liwen Wang, Baojun Pang, Min Lin, Kai Zhang, Yong Chen, Shaoheng Wang. Reactive powder concrete after high temperature mechanical properties research. [J] vibration and shock, $\mathrm{v}$. 31;No. 18016:27-32, (2012) 